\title{
Intelligent Design Theory
}

\author{
Sachin Kumar \\ 207/4 Block-3, Khurbura, Dehradun (Uttrakhand), INDIA
}

\begin{abstract}
The theory of evolution by natural selection, proposed by Charles Darwin \& Alfred Russel Wallace to count for the diversity of species of life on earth in the recent years has been challenged by scientists worldwide based on a new scientific theory called the 'ID' or Intelligent Design theory. This paper gives an overview of the Intelligent Design Theory. It discusses the shortcoming of the Darwin's theory of evolution. Different theories of how life originated from the nonliving matter including the Replicator First Theory \& Metabolism First Theory have been discussed in brief and it has been analyzed how these theories fails to explain the complexity of real world. Finally a mathematical analysis has been done of some real life examples to compute the probabilities of existence of the world as we see it absent the Intelligent Design.
\end{abstract}

Keywords: Intelligent Design Theory, Theory of Evolution, RNA, DNA

\section{Introduction}

Though the idea of ID existed much before the birth of Charles Darwin. The best example is of English theologian William Paley, creator of the famous watchmaker analogy. Paley wrote in 1802 that if we find a watch in the field, we immediately infer that it was designed by some human intellect, there is a designer behind it $\&$ it is not by some natural process acting blindly $\&$ uncontrolled. The argument from design prevailed as an explanation of the world $\&$ all living creatures until the publication of Origin of Species in 1859. Charles Darwin was somehow able to convince the scientists that evolution by natural selection better explained life's complexity \& diversity. In some circles however, opposition to the concept of evolution has persisted to the present. The argument from design has recently been revived by a number of intellectuals \& academicians who have strong faith in ID.

\section{Loop Holes in the Darwinian Theory of Evolution}

In the scientific community we use the term Black Box to define a system whose inner workings are unknown.To Charles Darwin and his contemporaries the living cell was a Black Box because they were totally unaware of the fundamental mechanisms of the cell. But today we are aware that the cell is not such a simple structure rather a complicated assembly of very microscopic molecular machinery.

Hence assuming that the smallest working unit of life would have been a very simple structure is itself erroneous. How can we decide that whether Darwinian natural selection can account for the amazing complexity that exists at the molecular level? Darwin himself set the standard when he acknowledged that -

"If it could be demonstrated that any complex organ existed which could not have possibly been formed by numerous, successive, slight modifications, my theory would absolutely breakdown."

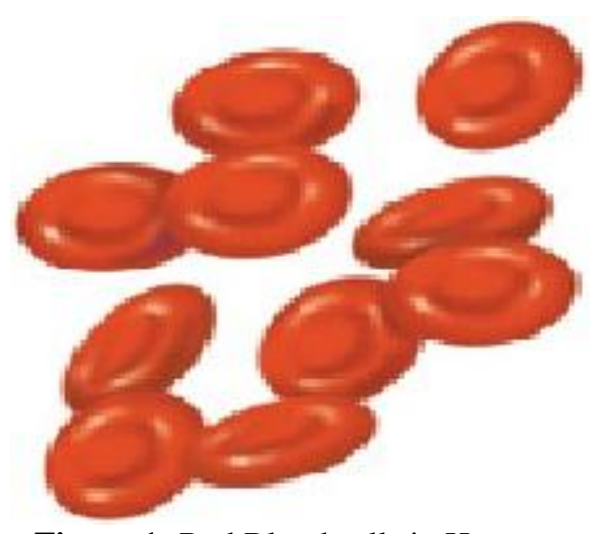

Figure 1: Red Blood cells in Humans

Irreducibly complex systems may appear very unlikely to be produced by numerous, successive, slight modifications of prior systems, because any precursor that was missing a crucial part will fail to function at all. Natural selection can only choose among the systems that are already working. An example of irreducible complexity is the system that allows protein to reach the appropriate sub cellular compartments where specialized tasks take place. Proteins reach their proper destination only with the help of signals chemicals that turn on and off certain reactions at appropriate times.

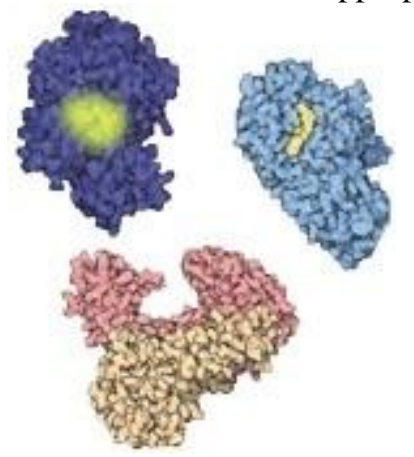

Figure 2: Enzymes that are proteins that facilitate chemical reactions

All parts must function in synchronism or else the system breaks down one most fundamental thing that makes Darwin's theory unacceptable is the irreducible complexity. Take the example of a bow to support the above statement it is very simple to construct and requires only two things a bent stick and a string. But for the bow to function it requires both the stick and the string to function 


\section{International Journal of Science and Research (IJSR) \\ ISSN (Online): 2319-7064 \\ Index Copernicus Value (2015): 78.96 | Impact Factor (2015): 6.391}

simultaneously. It is not that with a stick alone I could fire an arrow to 100 meter and if I attach string to it I could fire the same arrow to $200 \mathrm{mtr}$, it doesn't makes any sense. For a bow to function both the stick and the string have equal importance. Many Biochemistry scientists frankly admit their bewilderment about how the molecular life may have originated, but they refuse to accept the obvious fact that molecular machines appear to look designed because they really are designed. Creation of something out of nothing makes no sense and so the claim that life originated out of the nonliving itself is erroneous.

\section{Living from the non living}

Theories of how life originated from the nonliving matter fall into two broad classes these are Replicator First Theory \& Metabolism First Theory.

\subsection{Replicator First Hypothesis}

It supports the assumption of a large molecule capable of replicating itself (such as RNA) formed by chance. Replicator First theorists must explain how such a complicated molecule was formed before the process of evolution was underway.

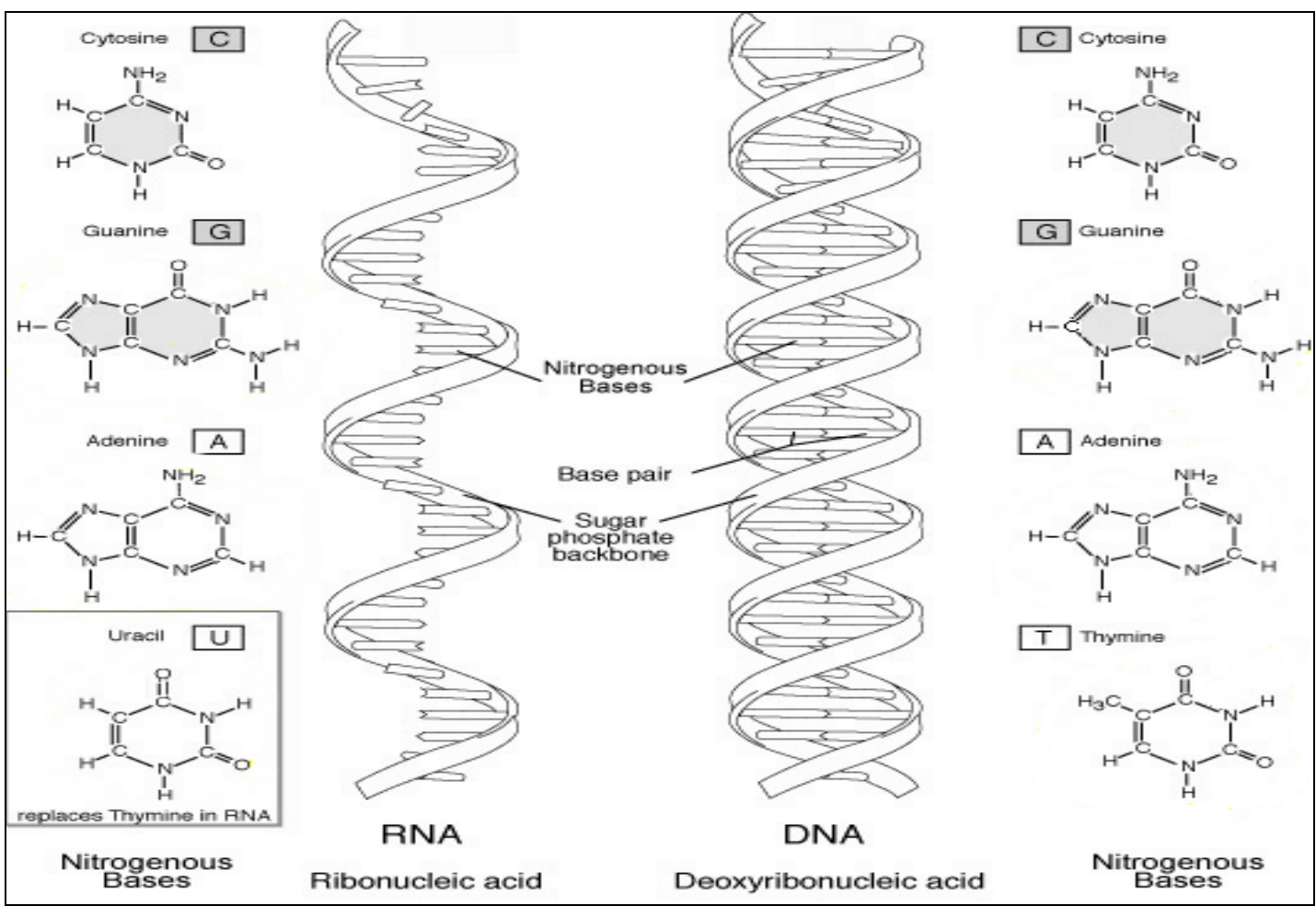

Figure 3

The RNA first hypothesis faces a tremendously challenging question. How did the first self replicating RNA arise? RNA building blocks, nucleotides are complex substances. Each RNA nucleotide contains some carbon atoms, numerous nitrogen atoms, oxygen atoms and phosphate group all connected in a precise 3-dimensional pattern. Many alternative ways exists for making those connections making millions of stable organic molecules that certainly are not nucleotides. Thus RNA first hypothesis suffers from this lethal defect. Furthermore it is unclear that how prebiotic conditions could have produced RNA molecules. However even if RNA is produced somehow by chance RNA'S very poor chemical stability hardly would have allowed the molecules to survive unprotected long enough to play a role in the initial chemical evolution of life.

\subsection{Metabolism First Hypothesis}

It says that small molecules formed an evolving network of reactions driven by an energy source. Metabolism First supporters must prove that reaction network capable of growing \& evolving would have formed. Furthermore for a living organism to be formed things should be in order however the entropy of the universe always increases this seems to violate the Second law of Thermodynamics, still to add on to the complexity it requires a continuous energy supply which requires an energy source which is still unexplainable.

\section{Intelligent Design}

William Paley reasoned that like the watchmaker analogy, the natural world contains abundant evidence of a supernatural Creator. ID is a scientific theory which has its roots in information theory and observations about the intelligent actions. ID theory makes inferences based upon the observations on the type of information that can be produced by purely natural processes to infer that life was designed by Intelligence, and Intelligence necessitates the presence of an Intelligent. ID states that intelligent action was involved at some point with the origins of the various aspects of biological life.

Intelligent Design theory begins with observations about the types of information that we can observe produced by 


\section{International Journal of Science and Research (IJSR) \\ ISSN (Online): 2319-7064 \\ Index Copernicus Value (2015): 78.96 | Impact Factor (2015): 6.391}

intelligent living agents in the real world. Even the atheist Zoologist Richard Dawkins says that intuitively, Biology is the study of complicated things that give the appearance of having been designed for a special purpose.

\section{Mathematical Analysis}

Now we will try and analyze the various real world situations mathematically.

\subsection{Case- 1. Human Eye}

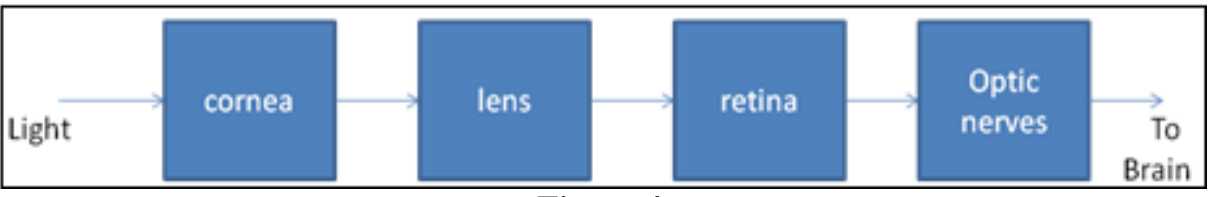

Figure 4

Fig4 shows a simple block diagram of the human eye, only four parts of the eye are considered to reduce the complexity involved. If we try to analyze mathematically how many different combinations are possible using these four blocks it can be worked out as:

Using permutations and combinations total possible arrangements $(\mathrm{T})$ are given by

$$
T=4 p 1 \times 3 p 1 \times 2 p 1
$$

$T=4 ! /(4-1) ! X 3 ! /(3-1) ! X 2 ! /(2-1) !(2)$

$T=4 ! / 3 ! X 3 ! / 2 ! X 2 !$

$\mathrm{T}=24$.

So we see that there are total 24 combinations possible this is much less compared to the actual number of possible outcomes with many components of the human eye and its complex structure. Out of the total 24 combinations only 1 is successful and the other 23 are not, any of the 23 combinations will render us blind unable to see the world. If we try and figure out the success rate in percentage it will come to about -

Success $\%=1 / 24 \times 100 \%<5 \%$. Thus we see that the possibility of success is less than $5 \%$ with $95 \%$ chance of failure. But in real world we see a high rate of success and the combinations are in nearly $95 \%$ cases correct. This itself is a proof that this is not a blind process but a precisely controlled one. This control necessitates Intelligent design claiming just natural selection to be responsible for such high success rates sounds little impractical.

\subsection{Case-2 Mathematical analysis of Natural selection}

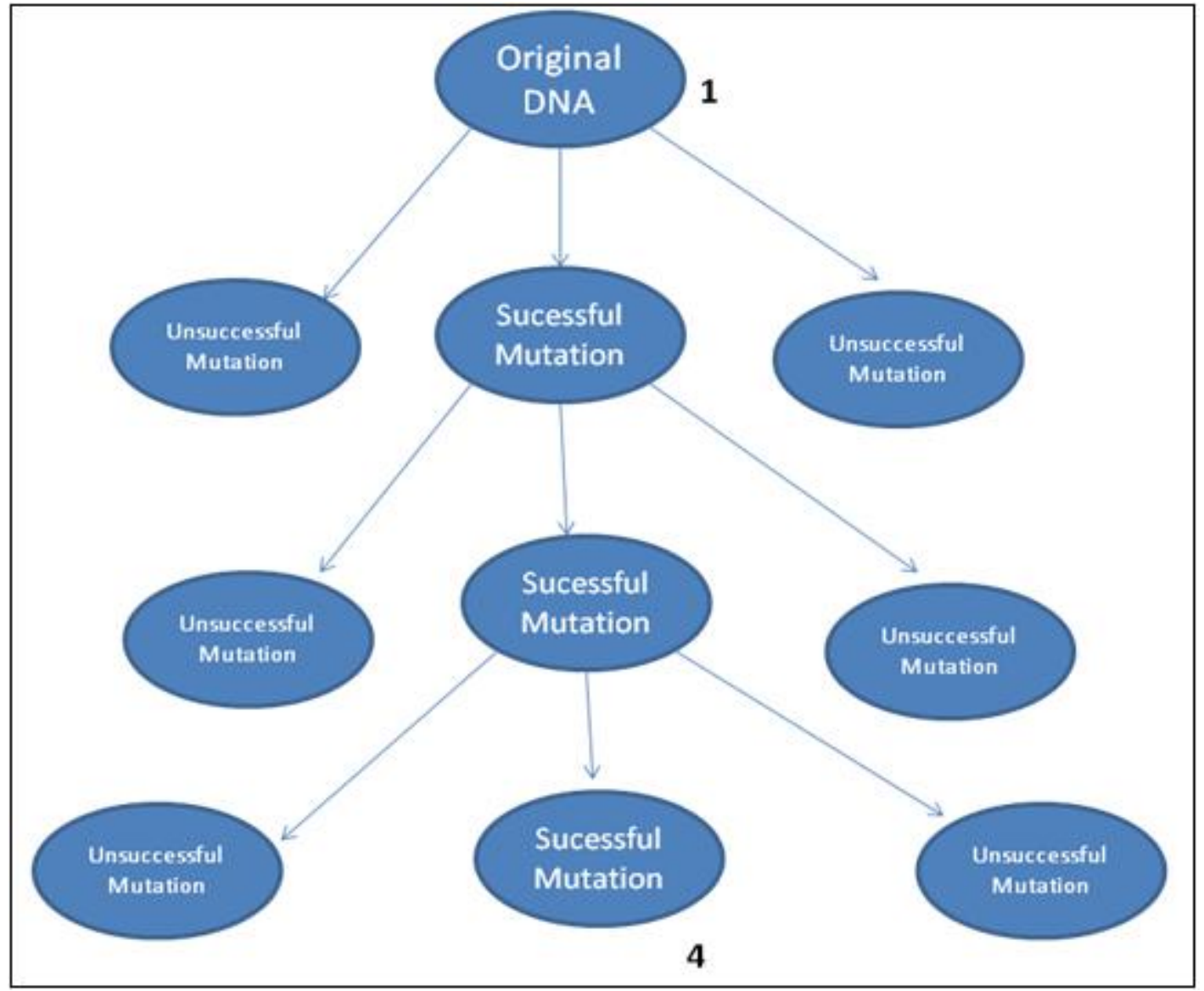

Figure 5 


\section{International Journal of Science and Research (IJSR) \\ ISSN (Online): 2319-7064 \\ Index Copernicus Value (2015): 78.96 | Impact Factor (2015): 6.391}

Refer Fig5, If we try to find out the probability of reaching from 1 to 4 the final successful mutation starting from the original DNA it would be -

Total probability $(\mathrm{P})$

$$
\begin{aligned}
& P=p 1 \times p 2 \times p 3 \\
& p 1=p 2=p 3=1 / 3 c 1 \\
& P=1 / 3 \times 1 / 3 \times 1 / 3 .
\end{aligned}
$$

$\mathrm{P}=1 / 27$

Success rate being $<4 \%$.

This figure clearly shows that the survival of species will be really difficult with nearly

$96 \%$ chances of extinction, but that is not how the real world works.

\subsection{Case- 3. Analysis of Cells \& Proteins}

The cells are complex structures and basic building blocks of living beings. For carrying out various jobs cells make use of protein. Each type of protein is a specialist and carries out a specialized job only. So to carry out a specific job the cell must create a specific protein only. Proteins are made up of 20 types of different Amino Acids the sequence of amino acids in the chain determines the protein type and its specific function. If we consider that to carry out a specific job a cell requires a protein $\mathrm{ABCD}$ of 4 Amino acid say $\mathrm{A}, \mathrm{B}, \mathrm{C} \& \mathrm{D}$. If we try and find out different proteins that can be made out of these 4 amino acids it will turn out to be -

$\mathrm{N}=24$.

$$
N=4 p 1 \times 3 p 1 \times 2 p 1
$$

So the probability that the cell will make the required protein is $1 / 24$. This gives a Success rate of

$$
1 / 24 \times 100 \%<5 \%
$$

Thus this proves that $95 \%$ times the cell will fail to do the required job which will lead to critical failure of the biological machinery.

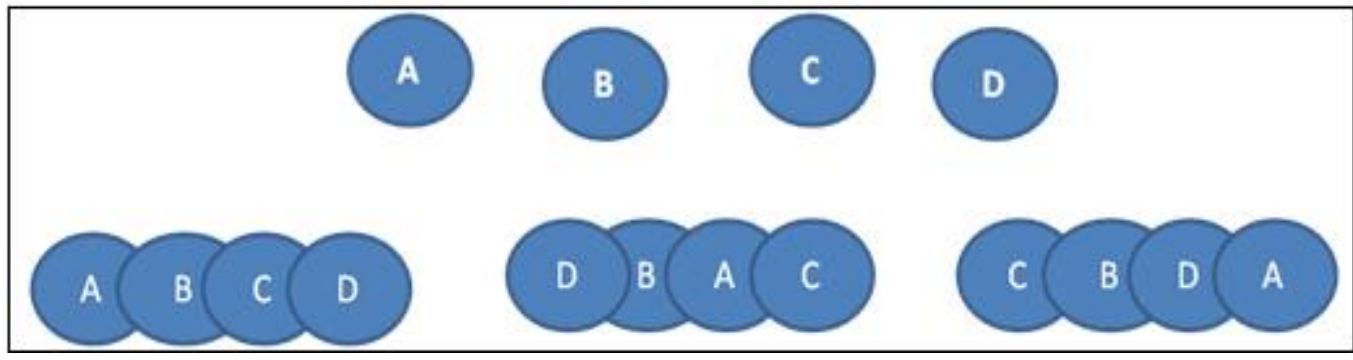

Figure 6: Different Protein formation using combinations of Amino Acids

\section{Conclusion}

We have discussed in brief an overview of Intelligent Design Theory. We also discussed the various shortcomings of the Theory of Evolution by Charles Darwin and the Theories of origin of life from the non living including Replicator First Hypothesis \& the Metabolism first Hypothesis. Finally we did an mathematical analysis of a few real world examples from which we could draw this inference that the existence of the world seems to be mathematically extremely difficult without Intelligent Design. All this discussion allowed us to draw some conclusions regarding the origin of life on earth, Intelligent Design Theory is more logical and reasonable approach to account for life on earth as opposed to Darwinian's Evolution \& Natural selection. DNA, RNA, Proteins \& other molecules must be set aside as only participants in the origin of life $\&$ not as a source of life.

\section{References}

[1] Biology- Campbell Reece $10^{\text {th }}$ edition year 2013.

[2] Biological Thermodynamics- Donald Haynie $2^{\text {nd }}$ edition year 2008.

[3] Introduction to Bioinformatics - Stephen A Kraneltz, David D Woruble. Year 2003

[4] New Scientist -Nov 2006.

[5] Scientific American -June 2007, Dec 2008. 